\title{
Arbor
}

\section{Mujeres en la Ciencia}

\section{Ángel Martín Municio}

Arbor CLXXIX, 706 (Octubre 2004), 549-566 pp.

Vamos a comentar en este rato los esfuerzos de las mujeres a lo largo de la historia para penetrar en los diferentes campos de la ciencia y los éxitos conseguidos. Actitud que se integra en lo que se ha llamado la larga marcha de la mujer hacia la igualdad, desde el ayer hacia el mañana. Larga marcha a través de un cambio radical en la estructura social y económica, y el estilo de vida de las mujeres en la mayor parte del mundo. Cambio que lleva consigo, no se si como causa o como efecto, el matrimonio más tardío, el menor número de hijos y su advenimiento más espaciado, y la prolongación de la vida de la mujer. La mayor duración de la adolescencia de las jóvenes las permite enfrentarse a nuevas expectativas culturales; la maternidad, aunque siga cumpliendo un papel social central, está dejando de ser la finalidad toda de la existencia de la mujer; la vida más prolongada como simple reflejo de su mejor calidad no deja de tomar parte en la estructura familiar, el desarrollo económico y la dinámica de las poblaciones. Y, a pesar de esta marcha y de este cambio, aún son mujeres los dos tercios de los 800 millones de analfabetos que existen en el mundo; cada año, medio millón de mujeres mueren por causas relacionadas con la maternidad; cien millones de jóvenes han sufrido mutilaciones sexuales; en distintas partes del mundo, los fundamentalismos religiosos intentan reducir los derechos con muchos esfuerzos conseguidos por las mujeres en orden a la educación, a la salud, al empleo, a la libertad de expresión o al control de la fertilidad; sólo en los Estados Unidos, cada ocho segundos una mujer es objeto de malos tratos y cada seis minutos ocurre una violación; en Africa, de cada diez infectados de sida, seis son mujeres.

«La larga marcha de las mujeres hacia la igualdad» ha sido el título del suplemento de Le Monde», con motivo de la conferencia mundial de Pekin hace pocos meses. En el artículo de cabecera, de Michèle Aulagnon, 
se lee: "La atmósfera que envuelve la inauguración de la conferencia mundial de las Naciones Unidas sobre la mujer, el lunes 4 de septiembre, está cargada de electricidad. Al entusiasmo de las tres conferencias precedentes, 1975 en México, 1980 en Copenhague, y 1985 en Nairobi, ha sucedido la inquietud. Los derechos de la mujer no solo no progresan sino que se ven amenazados. El principio mismo de igualdad, tal como figura en la carta de las Naciones Unidas de 1945, está hoy en tela de juicio. Un cierto número de Estados rechazan la idea de igualdad entre los sexos y prefieren el término de equidad. La cuestión no es simplemente formal, ya que si la igualdad impone que hombres y mujeres sean tratados de la misma manera, la noción de equidaad es mucho más elástica. A esta cuestión de fondo, disimulada bajo apariencias lingüisticas, se superpone una constante preocupación. La lucha contra la discriminación marca el paso. $Y$ aunque se hayan realizado progresos sensibles en los dominios de la educación y la salud, la mujer se siente bajo un techo de cristal en el acceso al trabajo o en la participación del poder político. Por otro lado, las crisis económico-sociales con las que se enfrentan tanto los paises desarrollados como aquellos en vías de desarrollo, fragilizan algunos de los resultados conseguidos. De esta forma, la pobreza y la violencia se ceban particularmente sobre las mujeres y comprometen los logros de los últimos veinte años".

Vamos a examinar cómo se han traducido estas inquietudes, a lo largo de la historia de la humanidad, en los campos de la creación científica, y, particularmente, cómo las mujeres han alcanzado los premios Nobel, una de las metas ideales de esta marcha. Avancemos que desde la creación del premio Nobel, en 1901, de las 634 distinciones hasta el pasado agosto, sólo 28 lo han sido a mujeres; y de entre ellas, 12 lo han compartido con hombres. A ellos hay que añadir, el concedido a primeros de octubre del presente año a Christiane Nuesslein-Volhard, la primera mujer alemana galardonada con este premio en Medicina y Fisiología, por sus trabajos sobre biología del desarrollo, si bien compartido con otros dos varones, Edward B.Lewis y Eric Wieschaus.

Esta marcha se inició hace muchos cientos de años. Durante ella, Aristóteles mismo antes de Cristo, y Santo Tomas de Aquino en el siglo XIII, hablaban de las diferencias entre hombre y mujer en cuanto a la implantación gradual del alma durante su respectivo desarrollo embrionario y fetal. Las teorías de los antiguos griegos estaban basadas, lógicamente, en la interpretación de los simples hechos observados, y fueron aceptadas por Tomás de Aquino en el sentido de que el alma completa su implantación a los 40 días en los embriones masculinos, y a los 
90 días en los femeninos. Hace, sin embargo, tan sólo medio siglo de la demostración de que las primeras señales histológicas del desarrollo sexual masculino, la aparición de los túbulos seminíferos, se detectan en los embriones humanos a las seis semanas, en tanto que las primeras señales del desarrollo femenino, los oocitos primarios, no ocurren hasta las once semanas. Hechos que van acompañados de una mayor velocidad. de desarrollo en los embriones masculinos que en los femeninos; lo que se traduce, después, en mayores velocidades metabólicas en el hombre que en la mujer, a lo largo de toda la vida; quizá, la razón por la que la expectación de vida del hombre es inferior a la de la mujer. Más modernamente, incluso Rousseau arguyó que la mujer tiene una naturaleza completamente distinta de la del hombre, y que esta diferente naturaleza la discualifica para su participación en la vida política. En contraste con esta idea, los hay que abogan por la feminización de la tecnología para lo que arguyen que los valores distintivos de la mujer han de tomar parte en el dominio público, si la tecnología, en efecto, ha de servir al bien común y promover el bienestar humano.

Con estos antecedentes, por muy remotos que algunos sean, podemos darnos cuenta de la distancia que ha habido que recorrer hasta que la mujer alcanzara su participación en la ciencia moderna, con sus renuncias, sus postergaciones y sus éxitos. Antes de entrar en el relato de algunos detalles sobresalientes de esta participación, y ante la pregunta de si a esta condición social y científica responde un cierto tipo de mujer, hay que adelantar que las ha habido bonitas, atractivas, vulgares y hasta descuidadas; casadas y solteras, con y sin hijos; independientes y subordinadas. Pero siempre han poseído el nivel propio de la comunidad científica, recibieran o no los galardones reservados a los triunfadores; y, además, nunca, por lo general, intentaron ligar el trabajo científico y su creatividad a unos valores específicamente femeninos. Ninguna se quejó nunca de sentirse extraña en su trabajo porque estuviese rodeada casi exclusivamente por hombres. Ni una sóla de ellas formuló la cuestión de si en la investigación científica ha dominado excesivamente el punto de vista masculino, ni si debiera ser completado con una perspectiva femenina.

A lo largo de esta intervención vamos a pasar revista a la actitud de una colección de mujeres frente a la realidad cotidiana. "Realidad cotidiana, ante cuya proximidad forzada -en palabras de Victoria Camps-la mujer ha podido desarrollar relaciones más afectivas y más pragmáticas, un lenguaje más concreto, claro y preciso, menos abstracto, una aproximación a las cosas más intuitiva. Son tópicos, sin duda, que se han repe- 
tido hasta la náusea, pero los tópicos no son falsos; tienen una base real que los sustenta....Las mujeres no han querido, o no se han atrevido, renunciar a nada: ni a los hijos ni a dejar de tenerlos, ni a llevar las riendas de la familia ni a soltarlas». Y, quizá, esta insistencia en lo impersonal de la investigación, la postergación de deseos, objetos y creencias privados, sea precisamente el secreto de las mujeres triunfadoras en los campos de la ciencia.

No caigamos, sin embargo, en el error bastante extendido de pensar que no hubo mujeres en la ciencia antes de los tiempos modernos. Hoy se conoce que hubo mujeres eminentes dedicadas a la ciencia, aunque, quizá, ignoradas por su historia. Desde la Antigüedad ha habido mujeres activamente dedicadas a las ciencias físicas, biológicas y médicas, así como a la ingeniería y a la tecnología. Hace 6000 años que se conoce a ciencia cierta esta participación, aunque se desconozcan sus nombres como el de las sacerdotisas médicas que aparecen en las cuevas de la época sumeria, unos 4000 años antes de Cristo. Se conoce ya, de todas maneras, el nombre de Merit Ptah que vivió en Egipto unos 2700 años antes de Cristo, se encuentra dibujada en una tumba del Valle de los Reyes, y ha sido descrita por su hijo, un sumo sacerdote, como médico importante. La primera mujer con participación en las ciencias físicas cuyo nombre ha llegado hasta nosotros es la química babilónica, Tapputi-Belatekallim, que vivió unos 1200 años antes de Cristo. Su nombre y lo que sabemos de su trabajo aparecen en escritos cuneiformes sobre tabletas de arcilla. Tapputi trabajó en la antigua tecnología química de producción de perfumes en Mesopotamia y fue autora de un texto sobre producción de perfumes. Durante los dos milenios y medio que transcurren desde los años 3000 a los 600 antes de Cristo, se ha calculado que la identificación de mujeres dedicadas a la ciencia ocurría al ritmo de una cada 250 años. Ritmo que se acelera de forma extraordinaria al pasar de los años 600 a los 200 antes de Cristo, durante los que el número de mujeres identificadas crece a unas 20 por centuria, con lo que se eleva unas 50 veces el número anterior. Este ascenso tiene como motivo fundamental el cultivo de la ciencia y la filosofía griegas en aquellos siglos, y refleja específicamente la preeminencia de las escuelas pitagórica y platónica, así como la promoción de la presencia de la mujer en ellas. Algunas de estas mujeres griegas fueron Theano, líder de la escuela pitagórica tras la muerte de Pitágoras; Artemisia de Caria, una de las más importantes botánicas de la antigüedad; Arete de Cyrene, con especial dedicación a la física y a la filosofía; y Pythias de Assos, importante zoóloga marina de la antigüedad. 


\section{Mujeres en la Ciencia}

Tras este período especialmente brillante del helenismo, a partir de los años 200 antes de Cristo, la participación de la mujer, con sólo algunos repuntes en el siglo I aC y tras el nacimiento de Cristo, va en descenso hasta alcanzar sus cotas mínimas durante las edades oscuras medievales. Durante los primeros siglos despues de Cristo hubo una gran cosecha de mujeres alquimistas; entre las que merecen citar Maria la Judía, muy famosa en la alquimia de su tiempo; María de Alejandría, diseñadora de instrumentos de laboratorio como el famoso baño de María, a ella dedicado. Pasa por ser la última gran personalidad científica de la Antigüedad, Hypatia de Alejandría, dedicada, alrededor del año 400, a las matemáticas y a la astronomía, en la Universidad de Alejandría. Fue quemada viva por los años mismos del incendio de la biblioteca de Alejandría, y representa uno de los personajes finales de la ciencia de la Antigüedad. Durante los diez siglos siguientes, las escasas mujeres que cultivan la escasa ciencia de aquella época oscura lo hacen, precisamente, en la medicina.

A partir del año 1000 vuelve a crecer, lógicamente, esta participación, debido sobre todo a la práctica de la ciencia en los conventos por las mujeres miembros de ordenes religiosas; y, así, a mediados del 1200, fie el cultivo de la ciencia por las mujeres superior a ningún otro tiempo de la historia. Mujeres singulares de este tiempo fueron Hildegard de Bingen, que pasa por la máxima autora de trabajos científicos de la Edad Media; Herrade de Landsberg, autora de obras enciclopédicas acerca de la tecnología medieval; y la famosa Heloisa, heroína de la historia de amor con Abelardo, y, a la vez, matemática y física, e intelectual relevante de la época. No deja de ser curioso señalar cómo tras la brillante participación de la mujer en la edad de oro del escolasticismo, en el siglo XIII, durante el periodo que transcurre a través de la alta Edad Media y el Renacimiento (XIV al XVII) se da una gran estabilidad en la participación cuantitativa de la mujer, a pesar del gran resurgir intelectual de estos siglos y de la gran reactivación de la ciencia, el arte y la literatura. Entre las causas capaces de interpretar esta reducción se han tenido en cuenta la peste bubónica que terció la población europea en el siglo XIV, la guerra de los cien años, la Reforma y el cierre de conventos en el XVI, y la persecución y tortura de las mujeres en toda Europa, durante varios siglos, acusadas de brujería.

Tras esta historia, hay que subrayar la presencia en el siglo XIX de tres mujeres excepcionales en el cultivo de las matemáticas. Sophia Germain, nacida en París en 1776, cuyas investigaciones sobre los modos de vibración de las superficies elásticas merecieron el Gran Premio de la 


\section{Ángel Martín Municio}

Academia de Ciencias. Mary Somerville, nacida en Escocia en 1780, traductora y difusora de la Mecánica Celeste de Laplace. Y Sofya Kovalevskaya, nacida en Moscú en 1850, reconocida con el premio Bordin por sus investigaciones sobre el movimiento de un cuerpo sólido alrededor de un punto fijo; la primera mujer miembro de la Academia Imperial Rusa. Además de ellas, Lady Lovelace, hija de Byron, estudio matemáticas con Mary Somerville y colaboró con Babbage en sus pioneros desarrollos de la máquina de calcular.

En los primeros años del siglo XIX dos mujeres se distinguieron en la popularización de la ciencia, Margaret Bryan y Janet Marcet. Ambas hablaron y escribieron, principalmente, sobre física, química y astronomía. Son famosas las "Conversaciones sobre la química" de Janet, publicadas anónimamente en 1806, de las que se vendieron más de 150.000 ejemplares.

Y en los primeros años del mismo siglo XX, exactamente en 1903, nos encontramos con el Premio Nobel de Física, cuya cuarta parte correspondió a Maria Curie. Maria Sklodowska, polaca de nacimiento en 1867, con una enorme dedicación al trabajo y una gran ambición, logró continuar su formación científica en París. En una de sus biografías se recogen los párrafos siguientes: "La criatura mofletuda y regordeta que había llegado a París tres años antes se había transformado durante el tiempo de estudios, lleno de privaciones, en una delicada, diáfana y a la vez disciplinada joven mujer. Desde el último año en la universidad había tenido un admirador tan serio como tenaz, el físico frances ocho años mayor que ella, Pierre Curie, que trabajaba en un puesto relativamente modesto como profesor y jefe de laboratorio en la escuela fundada por la ciudad de París de Física y Química industrial........Pierre Curie cortejó de una forma poco usual a la polaca, casi esquiva $y$, desde un triste romance en su tiempo de institutriz, extremadamente precavida: no mandaba ramos de flores, sino separatas firmadas de sus publicaciones cientificas, y sus temas de conversación giraban casi exclusivamente en torno a la ciencia. Obviamente, tuvo éxito con ello: en julio de 1895, quince meses después de su primer encuentro, su prometida fue con él al registro civil». El premio se otorgó en partes iguales a Henri Becquerel y al matrimonio Pierre y Maria Curie por el descubrimiento y el trabajo pionero en el campo de la radiactividad espontánea y los fenómenos de radiación. Los Curie no asistieron a la entrega del premio, el 10 de diciembre en Estocolmo, alegando motivos de salud. Maria Curie fue, en efecto, una bella mujer, y, además, como ha señalado hace pocos meses la biografía publicada por 
Susan Quinn, fue no sólo una mujer excepcional y singular, sino una mujer que experimentó las mismas dificultades que otras por su ambición y su espíritu crítico. Fue amada apasionadamente por un colega científico, Paul Langevin, casado y padre de cuatro hijos, lo que no podía entender, o dejar de envidiar, el medio social de la época. Ese medio que, para su desgracia, nunca llegará a comprender esa maravillosa, mitad afirmación, mitad interrogante, que escribiría, como más adelante veremos, a finales de este mismo siglo, otra bella y nobel mujer, Rita Levi, en su autobiografía "EL ELOGIO DE LA IMPERFECCION»: "Si la disparidad evolutiva entre las facultades cognitivas y las emotivas de nuestro cerebro son la consecuencia de los procesos biológicos de los que no somos responsables, ¿̇podemos regocijarnos de pertenecer a esta especie expuesta a las trágicas consecuencias del predominio de lo emotivo sobre lo cognitivo en la guía de nuestra conducta?

Maria Curie, viuda desde 1906 en que Pierre murió en accidente de tráfico, obtuvo para ella solita el premio Nobel de Química 1911 por el descubrimiento de los elementos radio y polonio, la caracterización del radio y su aislamiento en estado metálico y la investigación sobre la naturaleza y los enlaces químicos de este elemento. Por aquellos años, Langevin retó en duelo a Gustav Téry por haberlo insultado en un artículo de prensa. Uno de los miembros de la Academia sueca escribió a Maria Curie incitándola a rechazar el premio y a no presentarse a recibirlo. Ella respondió, poco más o menos, que "el polonio era el polonio, y su vida privada era su vida privadan. Lo cierto es que Maria, entonces profesora titular de la Sorbona, acudió a Estocolmo acompañada de su hija mayor Irene, de catorce años, la que veinticuatro años más tarde se encontraría por sus propios méritos en la misma situación. Absurdamente, estos episodios arruinaron su nombramiento como miembro de la Academia de Ciencias de Francia. Murió Maria Curie en 1934 con un gran reconocimiento científico internacional, dedicada a la dirección de un magnífico laboratorio, el Instituto del Radio de París financiado conjuntamente por la Sorbona y el Instituto Pasteur; murió víctima de la ciencia que ella desarrolló, la radiactividad, y que produjo en su organismo una grave anemia perniciosa En nuestros mismísimos días en que la sociedad admite, y hasta aplaude, la paternal devoción del presidente Mitterand a su hija ilegítima, Francia ha honrado la memoria de Maria Curie depositando sus restos en el Panteón de hombres ilustres.

$\mathrm{Al}$ año siguiente de la muerte de Maria Curie, en 1935, su hija Irène Joliot-Curie, junto con su marido Frédéric Joliot, recibió el Premio Nobel de Química en reconocimiento a ls síntesis de nuevos elementos radiacti- 


\section{Ángel Martín Municio}

vos. Irène fue la primogénita del matrimonio Curie y pasó sus primeros años al cuidado material de su abuelo paterno el médico Eugène Curie, con lo que la joven madre pudo continuar sin interrupción y sin mayores preocupaciones sus trabajos. La hermana pequeña de Irene escribió acerca del abuelo: "El es el compañero de juegos, el maestro, mucho más que la madre, que está continuamente en el laboratorio, del cual los niños oyen hablar sin interrupción. A él no le basta con introducir a Irène en la historia natural y en la botánica, con compartir con ella su afición a Victor Hugo, con escribirle durante las vacaciones atractivas cartas, de lo más divertidas y llenas de ingenio; él es quien influencia la vida intelectual de ella en forma decisiva. El equilibrio espiritual de la actual Irène Joliot-Curie, su aversión a resignarse al pesar y al dolor, el sentido asociado a las realidades de la vida, su propio anticlericalismo y sus simpatías políticas las tomó directamente de su abuelon. Así pues, con una gran formación intelectual y científica, Irène siguió los pasos de su madre, se licenció en Física y Matemáticas; a los dieciocho años, durante la guerra del 14, dirigió un servicio de rayos $\mathrm{X}$ en un hospital anglocanadiense de la línea del frente. Su Tesis Doctoral, leída en marzo de 1925, versó sobre las oscilaciones en el alcance de la radiación á del polonio. En la portada de la Tesis se leía: "A Maria Curie de su hija y alumna".

Irène siguió, en lo científico y en lo privado, la andadura de su madre. La misma impresión frágil y enigmática; análogo el matrimonio como comunidad científica y reparto de cometidos; la misma timidez, severidad y rectitud; directora también del Instituto del Radio; el mismo entusiasmo por los hijos; la misma muerte mártir de la ciencia, como la madre. Ambos Hélène y Pierre continuaron la tradición científica de la familia; curiosamente, Hélène, dedicada como madre y abuela a la física nuclear, casó con un nieto de Paul Langevin. Llegó a ser Irène catedrática de la Sorbona y fue la primera mujer miembro de un gobierno, como secretaria de estado, en 1936, del gobierno socialista de Leon Blum. En cierta ocasión, a la pregunta de una periodista acerca de si la carrera que había elegido no era un tanto fatigosa para una mujer, contestó: "De ningún modo. Creo que la capacidad científica de un hombre y una mujer son completamente iguales. Irène Curie consideraba los compromisos familiares como posibles, bajo la condición de que fueran aceptados como una carga complementaria... Por mi parte creo que la ciencia será el interés principal en mi vidan.

Corrían, pues, en este relato, los primeros años del siglo XX y Florence Sabin, tan buena conocedora de la anatomía como de las matemáticas 


\section{Mujeres en la Ciencia}

y la zoología, fue la primera mujer que alcanzaba el profesorado en la Universidad Johns Hopkins. Después, en el Instituto Rockefeller, Florence dirigió un amplio programa de investigación sobre la química y la biología del bacilo tuberculoso y su responsabilidad en la instauración de la patología humana. Eran los primeros pasos de la formidable inmunología actual. Hasta su muerte, en 1953, a los 82 años, viajó por Europa y misionó la política de la ciencia y la naciente empresa de la salud pública. Fue Florence Sabin quien dió la bienvenida a Maria Curie en su visita, en 1921, a los Estados Unidos, y a su nombre se dedicó una de las primeras vacunas antipolio de la época actual.

Aquellos tiempos de la ciencia fueron los del Mycobacteerium, y Florence Seibert, víctima a los tres años de la primera epidemia de polio en los Estados Unidos, llevó a cabo la primera cristalización de las proteínas de la tuberculina. Superó con entusiasmo y coraje su defecto físico y acudió a Suecia para conocer de cerca los nuevos métodos de separación y análisis de las proteínas, que aplicó al estudio de las fracciones purificadas de la tuberculina y los tejidos sensibles. A Rebecca Lancefield se deben las primeras aportaciones rigurosas al conocimiento químico e inmunológico de los antígenos de estreptococos. A los 75 años fue elegida miembro de la Academia Nacional de Ciencias de los Estados Unidos, y aún prolongó su trabajo durante otros once años. Las revistas científicas de esa época recogieron sus investigaciones sobre virulencia y protección bacterianas, cuando Rebecca andaba por sus 80 años.

Tampoco es que en este relato intente espigar casos longevos, pero la verdad es que Alice Evans investigó hasta los 94 años sobre distintos tipos de bacterias patógenas. Fue la primera mujer presidenta de la Sociedad Americana de Microbiología y se contagió de brucelosis al comienzo de sus estudios, lo que le dió la ocasión de conocer durante largo tiempo, en realidad hasta su muerte en 1975 , todos los detalles de la enfermedad.

Margaret Pittman nació con el siglo, fue profesora de español y la primera mujer presidenta de la Academia de Ciencias de Washington. Ella trabajó en los tiempos y los lugares, y en los asuntos del cólera; y llevó a cabo un intenso estudio internacional que se prolongó hasta más de sus 80 años y, precisamente, a los 85 recibió Margaret el Premio Federal a las mujeres de la ciencia por sus logros excepcionales en el desarrollo de vacunas seguras y efectivas. Coetánea e igualmente longeva, $\mathrm{Pe}-$ arl Kendrick, estudiosa de las etiologías mixtas virobacterianas, fue contratada por la universidad de Michigan, a los 85 años, para enseñar 
la historia y el tratamiento de las enfermedades infecciosas, aún durante varios años, en la década de los setenta.

Por entonces estaba en un momento álgido el estudio de las enfermedades infecciosas, de sus agentes y de las reacciones del huésped; se acababa la transición de los arsenicales y las sales de oro hacia las sulfamidas y los antibióticos; la ciencia básica de los virus y de los mecanismos de acción antibacteriana sirven de fácil aplicación a las vacunas y los antimicrobianos de síntesis; la oncología viral se configura como uno de los campos más brillantes de la biología molecular. En este ambiente realizaron sus trabajos, durante largos años, Bernice Eddy y Sarah Stewart. Bernice lo hizo sobre el crecimiento de virus de polio en cultivos celulares y en el proyecto Salk de vacuna antipolio; suyas fueron las primeras revisiones sobre virus oncogénicos, cuando era vicepresidenta de la Academia de Ciencias de Washington. Las últimas publicaciones de Sarah, a los 70 años, trataron de los virus aislados de neoplasias humanas, de una de las cuales moriría después. En una de sus numerosas distinciones se puede leer: por su brillante, original, innovadora y resuelta dedicación.

Muchos, quizá la mayoría de los estudiantes de bioquímica del último medio siglo conocerán de Michaelis y Menten poco más, quizá nada más que su vinculación a la famosa ecuación de la cinética enzimática, conocida como de Michaelis-Menten. De forma que este guión que suele aparecer entre Michaelis y Menten confundirá a muchos que no sabrán si se trata de una persona sóla o de dos personas distintas; y, menos aún, que se trate de dos mujeres, Leonor Michaelis y Maud Leonora Menten, sin duda los dos nombres más referidos en la historia de las publicaciones de la especialidad. Estudiaban ambas, en 1913, la reacción conocida como inversión de la sacarosa cuando llevaron a cabo la contribución más fundamental en el campo de la enzimología, en el laboratorio aleman de Michaelis, al que había acudido la bellísima canadiense Maud.

Gerty Cori, austriaca de nacimiento, fue representante de la época heroica del metabolismo intermediario y de la gran enzimología de los azúcares en el cuerpo humano; y, por todo ello, Premio Nobel 1947, la primera mujer galardonada con este premio en Medicina y, a la vez, el primer Nobel femenino en los Estados Unidos. Los anteriores cincuenta premios Nobel en Medicina fueron concedidos a científicos varones. Y al igual que sus predecesoras las Curie, madre e hija, le fue adjudicado con su marido Carl Cori. Ella siguió a su marido, en 1931, como simple ayudante de investigación en el departamento de Farmacología de la Universidad Washington, en San Luis; y no deja de ser notable que en se- 


\section{Mujeres en la Ciencia}

mejante situación tuvo que permanecer durante 16 años, hasta que, en el mismo año 1947, obtuviera una cátedra de Bioquímica y el Premio Nobel de Medicina. La cooperación científica de Gerty, atractiva, pelirroja, alegre, inteligente, amante de la naturaleza, fue calificada como un tema delicado, que exige mucho dar y recibir por ambas partes $y$ ocasionalmente conduce a conflictos, cuando ambos son cónyuges con iguales derechos y no quieren ceder en su opinión. Un amigo del matrimonio describió de esta manera su complementación: "Sus procesos intelectuales se entremezclan, de modo que hablan y piensan en común. Cuando uno formula un pensamiento, entonces el otro lo recoge, lo despliega y lo adorna para, finalmente, alcanzar al primero, para que el otro pueda seguir completándolo....Su trabajo científico opera de la misma manera. Discuten en común experimentos y deciden cómo debe interpretarse lo que han visto. Cuando ellos resuelven una de sus esporádicas diferencias de opinión, entonces queda -al contrario que en la mayoría de los equipos de investigación- ventajosamente, en familian. Su opinión de la investigación científica, del trabajo y de la vida, se han recogido en una serie de discos bajo el título THIS I BELIEVE, «EN LO QUE YO CREO». En algún lugar se dice: "La honradez, que la mayoría de las veces alimenta la integridad intelectual, el valor y la amabilidad, son virtudes que siempre he admirado, aunque en el transcurso del tiempo se ha trasladado un poco el énfasis, y hoy día me parece la amabilidad más importante que en mi juventud. El amor al trabajo y la dedicación a él me parecen la base para ser feliz. Para un investigador, las ocasiones inolvidables de su vida son aquellos raros momentos, que llegan tras años de agotador trabajo arrastrándose hacia ellos, cuando se levanta de repente el velo sobre el secreto de la naturaleza y cuando lo que era oscuro y caótico, aparece en clara luz y con bella estructuran.

No deja de ser interesante señalar que en aquel año 1947, y a la misma universidad en San Luis, llegó la italiana Rita Levi-Montalcini, quien 39 años después, en 1986, recibiera también el premio Nobel por sus trabajos -como luego veremos- sobre los factores de crecimiento de los nervios.

Poco después, Dorothy Crowfoot, egipcia por nacimiento, aplicó en Cambridge la difracción de rayos $\mathrm{X}$ al conocimiento de sustancias de interés biomédico, en particular de la insulina y de la vitamina B12. Cuenta ella misma que su afición a la química, e incluso a los cristales, surgió de las enseñanzas en la propia escuela; lo hacía de esta manera: "Ya en la escuela primaria aprendí a hacer crecer cristales y lo encontraba una 
ocupación fascinante. Más tarde, en la escuela superior tuve un profesor de química muy bueno, $y$, dado que en esa escuela no se enseñaba ninguna otra asignatura de ciencias, no había realmente ninguna competencia y me decidí rápidamente a ser química. Cuando tenía quince o dieciseis años, ratifiqué a mi madre mi decisión, por la que me regaló el libro de William Bragg con sus conferencias de Navidad para niños titulado SOBRE LAS COSAS DE LA NATURALEZA». Allí describía Bragg cómo a través de la difracción de los rayos $\mathrm{X}$ puede ser explicada la estructura de los cristales y aseguraba que mediante esto podrían verse los átomos. $\mathrm{Y}$, al leerlo, Dorothy se preguntaba ¿de qué moléculas me gustaría más contemplar los átomos?. Su propia contestación era que la de las moléculas más importantes para la vida. Actitud que nos obliga a repensar en la importancia de la escuela y en la grandeza del papel de los maestros, desde los primeros años, en la formación de los niños y los jóvenes. Entre 1928 y 1932 realizó sus estudios de Química en Oxford; algo poco frecuente en aquella época, en que, entre todos los colegios de la universidad, solamente había cinco mujeres estudiantes de química. En Cambridge colaboró con el gran cristalógrafo Bernal en el famoso laboratorio Cavendish. Allí, uno de sus compañeros de trabajo fue Perutz, premio Nobel de Química 1962, quién, a la muerte de Dorothy, hace un año, escribió: "Dorothy Crowfoot, una imaginación brillante y una voluntad de hierro en busca del triunfo. Irradiaba amor, amor a la ciencia, a su familia, a sus amigos, a sus estudiantes....y a sus cristales". En 1964 recibió el Premio Nobel de Química, la tercera vez concedido a una mujer, por su contribución al esclarecimiento de las estructuras de interés biológico, utilizando la difracción de rayos X. Culta y afable profesora de química, cuyo intenso compromiso con la ciencia nunca fue incompatible con su responsabilidad familiar. Casó con el historiador africanista Thomas Hodgkin, con quien tuvo tres hijos: la hija es historiadora, y los dos hijos, uno botánico y otro matemático. Ambas dedicaciones, a la familia y a la ciencia, pudieron, incluso, ser compartidas con su cooperación a movimientos por la paz y el Tercer Mundo. Durante varias décadas, la esposa, madre y científica, se comprometió sociopolíticamente con el movimiento mundial de científicos contra el desarme nuclear. Murió el año pasado, como acabo de decir, octogenaria, dedicada a la naturaleza y a la arqueología; y, según su confesión con la televisión y la tostadora como únicas concesiones al confort de la vida moderna.

Este tipo de análisis de las estructuras químicas participantes de los fenómenos biológicos iba a permitir penetrar en el esclarecimiento de uno de los paradigmas fundamentales de la biología: la relación estructura- 


\section{Mujeres en la Ciencia}

función. Sin embargo, los secretos de la función de las moléculas aguardaban nuevos desarrollos metodológicos; uno de estos fue el de la dosificación de las hormonas. Por ello, por los procedimientos radioinmunológicos de análisis, utilizados hoy en todos los laboratorios del mundo, la neoyorquina Rosalind Yalow recibió su galardón Nobel de Medicina, en 1977.

Entrando un poquito en el terreno científico, comentemos que, por aquella época, algunas hormonas comenzaban a considerarse como factores de crecimiento, al estilo del factor de crecimiento nervioso que había descubierto Rita Levi. Hormonas y factores de crecimiento que actuan como señales extracelulares que luego se transducen mediante mecanismos singularísimos de interacción entre proteínas hasta llegar a gobernar multitud de efectos finales en las células; entre otros, los efectos sobre el crecimiento celular, la malignidad, las metástasis, etc. Pues bien, Rita Levi, hija de un acaudalado ingeniero de Turín, bella mujer judía, de gran elegancia y maneras altivas, hizo sus principales aportaciones a este descubrimiento en $1951 \mathrm{y}$, a pesar de todo ello, fue premiada con gran retraso, 35 años después, en 1986. Su falta de vocación para someterse al tradicional papel de esposa y madre lo relata así: "con veinte años me decidí por fin a decirle a mi padre que no tenía ninguna gana de ser esposa y madre, sino que prefería estudiar medicina. Mi niñera acababa de morir de cáncer, y un año más tarde murió también mi padre de un ataque al corazón. Eso me llevó inevitablemente a la medicinan. Posiblemente, sus notables recursos económicos y sus muy agraciadas condiciones físicas, unidos a un extraordinario vigor intelectual, pudieron ser causa, más o menos parcial, de otra importante declaración: "Nunca me he sentido discriminada como mujer en ciencia, aunque muchas mujeres si hablan de ello. Por el contrario, yo siempre he sido bien acogida por mis colegas masculinos. La comunidad científica me ha aceptado como un hombre. Como mujer, no he tenido problema de ninguna claser. A pesar de su decisión personal, a las jóvenes que intenten seguir la carrera de la ciencia aconseja: «no temas jamás a nada, tampoco al futuro. Cuando hagas algo, hazlo del todo y no a la mitad y además piensa bien con quién quieres compartir tu vida. Entonces conseguirás, si así lo quieres, jser esposa, madre y científica a la vez!

En una bonita autobiografía de Rita Levi, "EL ELOGIO DE LA IMPERFECCION", que he mencionado hace unos momentos, describe la imperfección como corolario del comportamiento del hombre: ¿podemos regocijarnos de pertenecer a esta especie expuesta a las trágicas consecuencias del predominio de lo emotivo sobre lo cognitivo en la guía de nuestra con- 


\section{Ángel Martín Municio}

ducta?" Párrafo que muestra la preocupación filosófica y religiosa de su aventura personal y científica, y de la vida en general; imperfección que otorga a cada uno sus oportunidades y sus riesgos, sus alegrías y sus sufrimientos. Admiradora de Cajal y de El Greco, cuando ya la ciencia rebosaba de las ideas promovidas por sus antiguos resultados, obtuvo el premio Nobel en 1986, tres años después del concedido a otro gran descubrimiento: el de cómo el cambio de lugar de los genes en los cromosomas puede alterar su función. Fue el descubrimiento de otra mujer, Barbara McClintock, cuyas sorprendentes observaciones y consecuencias, alrededor de 1950, se anticiparon a lo que su tiempo podía admitir. Algo así como lo que sucedió a Mendel, cuando al no encontrar el debido reconocimiento a la constancia de sus trabajos, en el jardín de su abadía, entre guisantes y vellosillas, afirmó: "mi tiempo está por llegar». Al igual que sucedió a Rita Levi, el premio llegó a Barbara, a sus 81 años, 33 años después de sus trabajos fundamentales. Espera que no sólo afectó a la concesión del gran premio; tuvo que aguardar décadas a alcanzar una posición profesional de cierta relevancia y a que los resultados fueran no ya admitidos, sino tan sólo dejados de ser ridiculizados por sus propios colegas. Sí que también es cierto, que Barbara era una mujer especial; estas son algunas de sus opiniones: "Me acuerdo de que me sentí emocionalmente atraida por algunos hombres, pero eran artistas en uno u otro sentido,no científicos....Esas relaciones no se hubieran mantenido, ninguna de ellas. Simplemente, no existía la fuerte necesidad de una relación personal con nadie.... Nunca pude entender el matrimonio. Aún hoy no lo entiendo. Nunca tuve la sensación de necesitarlo".

Y, efectivamente, practicó estas opiniones; nunca cultivó sus atributos femeninos, renunció siempre a relaciones superficiales y a cualquier tipo de actividades que no fueran las del estudio. Y no cabe duda que estas las cultivó con esmero, hasta tal punto que uno de sus biógrafos y compañeros ha dicho de ella: "He conocido a una gran cantidad de científicos; pero el único genio de verdad entre todos ellos, era Barbara McClintok». Si es cierto que Barbara fue singular en su actitud como mujer, no es menos cierto que sus trabajos, durante las décadas de los 20 y los 30 , cuando los resultados eran convencionales, fueron generalmente admitidos por la comunidad científica. Sin embargo, cesó el éxito científico cuando los resultados comenzaron a estar en desacuerdo con la tradición y en disonancia con los conocimientos genéticos precedentes. Sucedía, pues, que los resultados experimentales de Barbara no se ajustaban en absoluto con las leyes de Mendel; la presencia de numerosas manchas de colores diversos sobre los granos de maíz y la diversidad de sus formas, 


\section{Mujeres en la Ciencia}

variables en las sucesivas generaciones, se atribuyó a la inestabilidad de los genes implicados en la síntesis de los pigmentos. Tras cuidadosos y largos experimentos responsabilizó del fenómeno a un pequeño fragmento del cromosoma 9, capaz de trasladarse desde su localización original a otra próxima al gen responsable de la formación del pigmento. Así fue el descubrimiento de estos elementos controladores que alteran la función de los genes vecinos; pero -como ya he señalado anteriormente- ,y como ocurre de vez en cuando en la historia de la ciencia, estos descubrimientos y, seguramente, su mismo entorno sociocientífico, iban por delante de lo que eran capaces de admitir los paradigmas científicos del momento. $\mathrm{Y}$ al igual que en otros trances de la ciencia, la lenta maduración de la herejía dejó paso a la aceptación del fenómeno de la transposición de genes y a su interpretación en términos moleculares. Tuvieron que llegar, varias décadas después, algunos hechos experimentales de la importancia de la transferencia de la resistencia bacteriana a los antibióticos, la transposición de oncogenes de un cromosoma a otro en ciertas formas de cáncer, los mecanismos de acción de los virus tumorales, etc. para que, en su interpretación, se hiciera imprescindible acudir a los viejos descubrimientos de Barbara McClintock.

La constancia y la habilidad de esta mujer en sus trabajos sobre la variegación de los granos del maíz tuvieron a la larga su contrapartida en bacterias, animales y el hombre mismo; y legitimaron una cierta inestabilidad de la información hereditaria. Trabajos que tuvieron un paralelismo con los realizados con la mosca del vinagre. Quizá sea curioso que citemos algunas frases de la primera novela de William Golding, en 1954, "EL SENTOR DE LAS MOSCAS»: "La vida es una cosa científica, eso es lo que es....pero no se puede estar seguro de nada ¿verdad? Quiero decir, no del todo....Al otro lado de la pantalla de hojas el Sol vertía sus rayos y en el centro del espacio libre las mariposas seguian su interminable dan$z a$ m. En esta novela, Golding explora también el mundo en que vivimos. El descubrimiento y la creación de Barbara McClintock utiliza los métodos de la ciencia; el pensamiento de Golding usa las herramientas de la narración y del arte lingüístico. Y no deja, al menos, de ser curiosa la coincidencia de que ambos McClintock y Golding, recibieran en 1983 los premios Nobel, respectivamente, em Medicina y en Literatura.

En 1988, la farmacóloga americana Gertrude Elion recibió, a los 70 años, el Premio Nobel de Medicina; y, como en los casos anteriores, a los treinta años de sus investigaciones fundamentales sobre el metabolismo de células sanas y patológicas que ha permitido el diseño de nuevos medicamentos para el tratamiento de variadas enfermedades, tales como 
gota, herpes, leucemia, etc. Compartió el premio con su colega George H.Hitchings, de 83 años, director, en sus comienzos, de los trabajos de Gertrude, en la compañía farmacéutica Wellcome; por cierto, que la dirección de los laboratorios desaconsejó la contratación de Gertrude porque iba demasiado bien vestida.

Ocurre, sin embargo, con relativa frecuencia, al menos en los campos de la ciencia experimental, que entre las aportaciones científicas de los premiados y las de algunos otros no premiados existe una sutil línea de separación. Han sucedido, incluso, reclamaciones judiciales en diversas ocasiones. Situación que si, en efecto, ha perjudicado a los varones, con mayor frecuencia lo ha sido a las mujeres; y ello ha dado lugar a un notable número de historias paralelas de mujeres marginadas de la gloria por el simple hecho de ser mujeres. Son los casos de la serbia Mileva Maric, al lado de Einstein; Lisa Meitner, al lado de Otto Hahn; la china Chien-Shiung Wu, al lado de sus compatriotas Lee y Yang; Rosalind Franklin, al lado de Watson, descubridor de la doble hélice del DNA; Jocelyn Bell Burnell, al lado del Premio Nobel de Física 1974 Anthony Hewish; M.Grunberg-Manago, actual presidenta de la Academia de Ciencias de Francia, al lado de Ochoa. Evidentemente, no todos los casos, ni todas las situaciones fueron semejantes; pero, como idea general, en una biografía colectiva de estas mujeres se dice: "En el negocio de la ciencia domina una fuerte competencia, por lo que frecuentemente la arrogancia mostrada por los hombres tiene más éxito que la modestia y la timidez que muchas mujeres practican desde pequeñas. La capacidad de presentarse a sí mismas se encuentra poco desarrollada en casi todas las mujeres, sin que las científicas representen una excepción".

¿Qué ha pasado en las últimas décadas en el acceso de las mujeres al cultivo superior de la ciencia? ¿cómo ha ido cambiando esta participación?

En el último cuarto de siglo ha aumentado de forma significativa la participación de la mujer en la educación superior y en la ciencia. Las estadísticas de los Estados Unidos señalan la presencia de un $49 \%$ de mujeres del total de licenciados en 1970, llegando en 1980 a alcanzar la paridad con los varones; en la década de los 70 se duplicó el número de graduadas en ciencias de la computación, y se triplicó el de las que lograron graduarse en ingeniería. Si en los primeros años de la década de los 70 , el 14\% de los títulos de doctor fueron concedidos a mujeres, el porcentaje se elevó al 26\% en 1980; también, si en el lustro 1967-72 el 17\% del nuevo profesorado supuso el acceso a mujeres, el porcentaje se elevó 


\section{Mujeres en la Ciencia}

al 26\% durante el lustro 1975-80. Por lo que se refiere a las materias objeto del doctorado, las mujeres suponen el $40 \%$ del total en ciencias biológicas, el $35 \%$ de los doctorados en química, y sólo el 10\% en física. Hombres y mujeres acuden por igual a las instituciones más prestigiosas para realizar hoy los estudios e investigaciones doctorales.

En Inglaterra, en 1978, las mujeres representaban el $2 \%$ del total de profesionales de la ciencia, la ingeniería y la tecnología; porcentaje que se elevó al 5\% en 1988. El Comité de «Las Mujeres en Ciencia y Tecnología» del Reino Unido señala que, en el bienio 1990/91, aunque las mujeres representan el 23.7 del profesorado, solamente el 1.1\% han accedido a sus máximos niveles. Un informe de la National Science Foundation da la cifra total de 151.400 varones que enseñan ciencias en las universidades americanas, frente a 34.900 de mujeres -un $26 \%$ de aquellos-; a la vez, un $68 \%$ de los varones tienen contratos definitivos, en tanto que solamente los poseen un $36 \%$ de las mujeres.

En 1992, la situación de las mujeres en la ciencia sigue siendo compleja, pero sometida a un rápido cambio. En muchos campos se está difuminando la antigua discriminación frontal y se aprecia un claro aumento del número de mujeres que entran en el terreno de la investigación científica; sin embargo, parecen existir ciertos hechos singulares en algunos de los campos de la ciencia. Así, por ejemplo, en las neurociencias, la discriminación basada en el sexo ha desaparecido fundamentalmente, aunque ha sido reemplazada por obstáculos invisibles; en matemáticas, persisten las ideas sexistas y las mujeres se sienten aisladas y combatidas; la química se mueve entre ambos extremos.

Además de este avance, todo lo lento y desesperante que queramos, pero avance, a fin de cuentas, en las posiciones científicas individuales de las mujeres, hay que hacer notar la extraordinaria influencia colectiva de la mujer en la toma de decisiones globales. Buena muestra de ello ha sido recientemente la respuesta dada por mujeres de 70 paises, reunidas en una "Asamblea Mundial de la Mujer y el Medio Ambiente», para intercambiar experiencias acerca de la lucha contra la degradación ambiental. Asamblea celebrada en Miami, del 4 al 8 de noviembre de 1991, organizada conjuntamente por el Programa de las Naciones Unidas para el Medio Ambiente (PNUMA) y la organización internacional no gubernamental «WorldWIDE» (World Women in Defense of the Environment), cuyo objetivo es fomentar el papel de las mujeres en la gestión del medio ambiente. En dicha reunión se «fijaron criterios sobre la forma en que hombres y mujeres podían aunar esfuerzos para contribuir de manera 
concreta a la solución de los problemas ambientales en los planos nacional, regional y mundial». Dos grandes proyectos, entre los más de 200 presentados en la Asamblea, son ejemplo de las grandes posibilidades de esta actuación colectiva. Uno de ellos ha corregido en el estado de Andhra, en la India, la degradación de las tierras productivas, con la erosión de la capa vegetal superior, la obstrucción de los sistemas de avenamiento de las aguas, el aumento de la salinidad, la pérdida de cultivos de alimentos, y, lógicamente, la agravación del desempleo rural. En el otro, consistió en la disminución de las emanaciones de plomo y cadmio procedentes de una central metalúrgica en Brasil, con la consiguiente contaminación de aguas y los peligros de intoxicación cerebral y renal. 